\title{
Avaliar para aprender: a construção de uma realidade
}

GIOVANA CHIMENTÃO PUNHAGUI* NADIA APARECIDA DE SOUZA**

\section{RESUMO}

O trabalho apresenta a análise das práticas avaliativas do Certificado em Ensino de Língua Inglesa para Adultos (Celta), com o objetivo de compreendê-las como conjunto de açóes compromissadas com a avaliaçáo formativa, confrontando-as com as proposiçóes teóricas. Utiliza a abordagem qualitativa como metodologia para o desenvolvimento da pesquisa, sendo o relato de experiência a tipologia adotada. Analisa as práticas formativas sob a luz do referencial teórico e, a partir deste, por fim, aponta aprendizagens e tece sugestóes/contribuiçôes significativas relativamente às possibilidades e à viabilidade de exercer a avaliação formativa em sala de aula, evidenciando as consequências positivas de sua aplicaçáo para a aprendizagem do aluno.

Palavras-chave: Trabalho docente, Avaliação formativa, Processo de ensino-aprendizagem, Formação de professores.

\section{RESUMEN}

Este artículo presenta un análisis de las prácticas de evaluación del Certificado en Enseñanza de Inglés para Adultos (CELTA). Con el objetivo de comprenderlas como un conjunto de acciones comprometidas con la evaluación formativa, serán comparadas con las proposiciones teóricas. Como metodología para el desarrollo de la investigación se utiliza un enfoque

* Professora de língua inglesa e integrante do Núcleo de Estudos e Pesquisa em Avaliação Educacional (Nepae) da Universidade Estadual de Londrina (punhagui@hotmail.com). ** Professora do Departamento de Educação da Universidade Estadual de Londrina e pesquisadora do Núcleo de Estudos e Pesquisa em Avaliaçáo Educacional (Nepae) (nadia@uel.br). 
cualitativo y la tipología adoptada es el informe de la experiencia. Se analizan las prácticas educativas en base al marco teórico y a partir del mismo se señalan aprendizajes y se tejen sugerencias y contribuciones significativas sobre las posibilidades y la viabilidad de realizar una evaluación formativa en el aula, al hacer hincapié en las consecuencias positivas de su aplicación en el aprendizaje del estudiante.

Palabras clave: Trabajo docente, Evaluación formativa, Proceso de enseńanza-aprendizaje, Formación de profesores.

\section{ABSTRACT}

This paper presents the analysis of CELTA (Certificate in English Language Teaching to Adults) assessment practices in order to understand them as a set of actions committed to formative assessment, comparing them to theoretical propositions. It makes use of a qualitative approach as a methodology to develop the research, while resorting to experience reports as the typology adopted. It analyses its formative practices from a theoretical perspective and draws significant learning possibilities and contributions/suggestions about the feasibility of formative assessment in the classroom, highlighting the positive consequences its application may have on student learning.

Keywords: Teaching, Formative assessment, Teaching-learning process, Teacher training. 


\section{INTRODUÇÃO}

O Certificado em Ensino de Língua Inglesa para Adultos (Celta') é uma qualificaçáo inicial oferecida pela Universidade de Cambridge para pessoas que querem se tornar profissionais na área de língua inglesa e trabalhar com sujeitos falantes de outras línguas. Reconhecido pelo Conselho Britânico e pelo Instituto Britânico de Ensino de Língua Inglesa, o Celta é uma qualificação reconhecida internacionalmente e responsável pela formação de aproximadamente sete mil profissionais educadores a cada ano.

Realizar o curso em Londres, na Inglaterra, proporcionou intensas vivências em relação ao compromisso com a constituiçáo de sujeitos capazes de se expressarem na língua inglesa. No entanto, uma importante aprendizagem, dentre outras, despertou maior atenção: a viabilidade da utilizaçáo da avaliação formativa.

O interesse pelo campo da avaliaçâo escolar já era grande antes de participar do Celta. Todavia, ele se intensificou a partir da inserção e vivência de uma avaliaçáo de cunho formativo e orientou a decisão de estudar e aprofundar o tema, no intuito de compreender as formas concretas de efetivação de uma avaliação formativa. Apesar de um aparente "tecnicismo" na condução dos trabalhos lá desenvolvidos, foi surpreendente o comprometimento dos professores no acompanhamento das aprendizagens dos alunos. Mas, mais que o mero acompanhamento, toda uma sequência de estratégias interventivas era concebida e implementada no intuito de assegurar superaçóes.

Então, uma questão se instalou: compartilhar uma vivência de avaliaçáo formativa pode contribuir para a formação de professores avaliadores e para a melhoria da açáo docente? Mas outras inquietaçóes teimaram em emergir: a avaliaçáo Celta é efetivamente formativa?; quais as características de formatividade enunciadas pela avaliaçáo promovida no Celta?

A fim de elucidar as questóes propostas, estabeleceu-se como objetivo geral a orientar esse estudo: apresentar e analisar, consoante o referencial teórico, a conceituaçáo e proposta de uma avaliação compromissada com a formatividade, em consonância com as atividades do Celta.

\section{PERCURSO METODOLÓGICO}

Para que o objetivo geral fosse alcançado, escolheu-se a abordagem qualitativa. A opçáo por esta abordagem de pesquisa deu-se pelo fato de esta ter como 
foco o homem e seu cotidiano nos âmbitos político e social. Denzin e Lincoln (2006, p. 17) tratam do pesquisador qualitativo como um "confeccionador de colchas", em razão da gama de reflexóes e interpretaçóes que necessita realizar para melhor compreender a realidade investigada.

A abordagem qualitativa abarca interpretaçáo; subjetividade - mantida sob "rédeas curtas" quando a realidade é analisada tendo por respaldo o referencial teórico a desvelá-la; indutividade, quando vai encaminhando a tecitura das conclusóes na consideração do encontrado/vivenciado; processualidade, ao respeitar e considerar a progressão dos eventos. Esses aspectos foram percebidos no decorrer do estudo, náo só pela vivência da situação de formaçáo descrita - tanto no que concerne ao ensino quanto à avaliação -, mas quando sistematizando e descrevendo o experienciado pude aprofundar compreensóes ao mergulhar no referencial teórico.

A pesquisa, quanto à tipologia, configura-se em um relato de experiência. Todavia, mais que a descrição de vivências, o compromisso foi com a reflexão e o entendimento dessas, tendo por baliza o referencial teórico que elucida o significado de avaliaçáo formativa. Essa modalidade de pesquisa traz ao trabalho dados e interpretaçóes de uma vivência do pesquisador como participante de todo um processo. Desse modo, o procedimento de coleta de dados embasou-se na análise documental, fundamental para a configuração do vivido. Os procedimentos de análise dos dados se deram pela análise temática, ou seja, pela frequência com que alguns termos e/ou ideias se repetiam nos documentos investigados.

\section{AVALIAR O APRENDER OU AVALIAR PARA APRENDER?}

A fim de institucionalizar o processo educativo e sistematizar o saber - por razóes que náo cumpre explicar neste contexto -, o homem implanta, de forma gradual, a instituiçáo social escola, elemento constituinte de rede de relaçóes sociais voltadas a um determinado fim: a mudança no aprendente. A sua funçáo é transmitir os conhecimentos científicos considerados fundamentais para a construção do homem. A escola deve ser, então, lugar de aprendizagem, lugar de formação humana, pois se aprende para se formar o homem. De tal forma, todas as atividades desenvolvidas nesse espaço deveriam proporcionar aprendizagem, deveriam ser formativas, principalmente a avaliação da aprendizagem.

Nesse sentido, se avaliar integra o processo de aprendizagem, cabe a pergunta: avaliar o aprender ou avaliar para aprender? Para responder a questáo, é preciso entender qual a verdadeira diferença entre essas duas perspectivas e refletir acerca de qual delas seria caracterizada como formativa. Voltando o olhar para o primeiro 
conceito - avaliar o aprender -, vê-se em suas entrelinhas a avaliação de algo que já está acabado, já está pronto. Ou seja, avaliar o aprender seria avaliar o passado, o já efetivado, o já proposto e, quem sabe, o já aprendido num determinado período de tempo. Essa forma de avaliaçáo tem por foco a constataçáo e, portanto, prende-se e limita-se aos resultados.

Não concretizada a aprendizagem, é como se o aprendente ouvisse: "Sinto muito, mas o tempo de aprender isso já acabou!" Então, o professor acaba por imprimir um rótulo nos alunos e posiciona-os em um ranking, classifica-os, construindo hierarquias de excelência (Perrenoud, 1999). Náo estaria ele os privando do processo de aprendizagem? Álvarez Méndez (2002, p. 17), ao refletir a respeito da avaliação nestes moldes, afirma:

Avaliar somente no final, ou por unidade de tempo ou de conteúdo, é chegar tarde para garantir a aprendizagem contínua e oportuna. Neste caso e neste uso, a avaliação só chega a tempo de qualificar, condição para a classificação, que é o passo prévio para a seleçáo e para a exclusão racional. Ela desempenha funçóes distintas aos fins educativos, artificialmente necessárias, mas os principais beneficiados já não são os sujeitos que participam do processo. [...] Só lhes interessa (aos professores) a informaçấo dos dados, isolados de seus contextos, porém sobre eles são tomadas decisōes que resultam transcendentais na vida dos alunos.

Avaliar continuadamente é uma das possibilidades ofertadas para assegurar a evolução do aluno no processo de aprendizagem. Para além da nota ou das hierarquias de excelência, é fundamental que os procedimentos avaliativos favoreçam a compreensáo do conteúdo e forma da aprendizagem, possibilitando ao professor intervir oportuna e eficientemente e, ao aluno, investir esforços naqueles aspectos que reconhece frágeis.

Harris e McCann (1994) explicam as atitudes negativas, muitas vezes presentes nos processos avaliativos (preocupação excessiva com a nota, centralizaçáo do processo avaliativo na emissão de resultados: aprovado ou reprovado), como consequências de um divórcio entre ensino, aprendizagem e avaliação. Afirmam que a avaliação náo dá retorno acerca da qualidade e efetividade do processo de aprendizagem, pois é percebida como sinônimo de teste. Entretanto, sabe-se que teste é apenas um instrumento avaliativo, auxiliando na observaçáo do desenvolvimento do aluno. Em consequência, o retorno a este aluno é feito à base de números, letras, estrelinhas, luas ou sóis. A preocupação não se volta para a indicação de aspectos a serem aperfeiçoados, dificuldades a serem superadas, pois tudo se limita à produção e emissão de um escore. 
Além disso, importa destacar características proeminentes deste tipo de avaliação e que são abordadas por Black e Wiliam (1998). Eles as classificam em: (a) aprendizagem náo efetiva, (b) impacto negativo e (c) papel gerencial da avaliação. Tratando-se da primeira característica, os autores atentam para a aplicaçáo de testes que trazem uma aprendizagem muito superficial, nấo buscando no aluno conteúdos realmente significativos para sua formação. Segundo os autores, este seria o resultado da náo comunicação entre professor-aluno e professor-professor, sendo que há a necessidade da troca de experiências para promover o processo de ensino e aprendizagem de maneira a beneficiar os estudantes. Outro elemento negativo seria a ênfase na quantidade e apresentação de trabalhos, ao invés da qualidade em relação ao ensino, ou seja, muitos trabalhos e testes são aplicados a fim de impactar pais e demais responsáveis, diminuindo a qualidade da aprendizagem efetivada.

A segunda característica contempla a atribuição de notas e classificação dos alunos ao invés de proceder ao aconselhamento e dirigir o foco para a aprendizagem. Isto gera comparaçóes e competiçáo por notas, levando à exclusão de alunos com maiores dificuldades. Além disso, o feedback promovido pelo professor mostra aos alunos, considerados fracos, sua não aptidão para aprender.

A terceira e última característica, referente ao papel gerencial da avaliação não formativa, restringe-se à evidenciação de uma coleção de notas, em vez de enfatizar a análise do trabalho realizado pelos alunos, desconsiderando as suas reais necessidades. Os professores sabem pouco dos conhecimentos de seus alunos e, portanto, os feedbacks promovidos propiciam poucas referências acerca dos procedimentos cognitivos empreendidos na aprendizagem ou em relaçáo aos conteúdos apropriados.

Avaliar a aprendizagem é etapa do processo, não podendo constituir-se no seu fim. Até porque, como apresentar notas sem promover soluçóes ou aconselhamentos a respeito da recuperaçáo de saberes? Black e Wiliam (1998) apontam para a necessidade da criaçâo de uma "cultura de sucesso" em sala de aula, assim como anteriormente haviam afirmado Bloom, Hastings e Madaus (1983), ao defenderem o princípio da aprendizagem para o domínio, alicerçada na crença de que todos os alunos podem alcançar o conhecimento. Neste sentido, avaliar para aprender tornase ação poderosa se utilizada da maneira correta.

Observando a atividade de avaliar o aprender como não formativa, cabe explicar porque avaliar para aprender seria, então, considerada formativa. Segundo Black e Wiliam (2009, p. 9, tradução nossa),

A prática em sala de aula é formativa quando evidências sobre as conquistas do aluno são obtidas, interpretadas e utilizadas pelos professores, alunos ou seus co- 
legas para tomar decisóes a respeito dos próximos passos, no processo de ensino e aprendizagem, que são provavelmente melhores, ou melhor fundamentados, do que as decisóes que eles teriam tomado na falta da evidência obtida.

Analisando as consideraçóes tecidas pelos autores, observa-se a diferença entre avaliar o aprender e avaliar para aprender. Para eles, avaliar para aprender tem um caráter de incompletude e de possibilidades, quando apresentam a avaliaçáo como parte da dinâmica de sala de aula e essencial para a composição dos encaminhamentos da ação docente.

A avaliação realizada no intuito de obter informaçóes que favoreçam a recomposição do ensino em benefício da aprendizagem tem por ponto de baliza as produçóes e realizaçóes do aprendente. Todavia, o foco náo está no que ele já alcançou, mas naquilo que precisa atingir com o apoio do professor - superando dificuldades. Se o professor náo observa e avalia os saberes dos alunos e não os instiga a analisar e refletir a respeito de suas produçóes e das produçôes dos colegas, não há como programar novas atividades. Assim, percebe-se a importância da utilização da produçáo do aluno para planejar e efetivar encaminhamentos posteriores.

A avaliação para a aprendizagem - compreendida como uma avaliação formativa - envolve diretamente a interação professor e aluno. Black e Wiliam (2009) descrevem alternativas para essa interação, quando o intuito é proporcionar uma avaliação voltada para a aprendizagem. Esta interação deve estar centrada em estímulos externos e feedback, bem como na produção interna individual do aluno, estando alicerçada em três grandes pontos: iniciação-resposta-avaliação. Ou seja, primeiramente o professor propóe uma atividade para o aluno, o aluno responde a ela, e o professor, entáo, pensa e compóe uma próxima intervenção baseada naquela resposta. É esta a dinâmica da avaliaçáo contínua em sala de aula. O aluno é avaliado constantemente em sua prática, para que as evidências sejam utilizadas a favor de sua aprendizagem.

No curso Celta, a proposta desenvolvida para a formação de professores de língua inglesa tem por objetivo o trabalho com as evidências dos alunos para proporcionar outras situaçóes, concebidas e implementadas para promoverem a aprendizagem. Ainda, cada um dos alunos é envolvido no processo, instigado a buscar conhecimento e a observar o próprio desempenho. Utilizando a descriçáo da interaçáo professor-aluno, desenvolvida por Black e Wiliam (2009), pode-se aplicá-la em maior ou menor amplitude no decorrer do curso. Colocando-a em um quadro geral (maior amplitude), as sessóes de input, organizadas e proporcionadas pelos tutores, 
são a iniciaçáo do processo. Ali, os tutores orientam as discussóes e pesquisas, bem como norteiam as rotas de conhecimento a serem seguidas. As práticas de ensino são a resposta dada pelos alunos ao trabalho feito durante a iniciação. É o momento de o aluno Celta colocar em prática os conhecimentos buscados. É nesta etapa que o tutor fará a observação e a avaliação do desempenho do aluno com relaçáo aos objetivos traçados para aquele momento.

Ao observar a interação em menor amplitude, as sessões de input abarcam as três etapas do processo, sendo esta interação proporcionada pelo professor e tendo o aluno como colaborador e componente central. A cada disciplina ministrada, o professor lança propostas e monitora as respostas dos alunos. As mesmas são anotadas em seus registros docentes e farão parte da avaliaçáo geral de cada aluno.

Outra interaçáo em menor amplitude seria o trabalho com projetos propostos. A ideia desses projetos configura-se o princípio da interação. Para dar respostas a esta iniciação, é papel do aluno buscar informaçóes e o auxílio do tutor, que somente orientará caminhos, não proporá respostas. Após a entrega de cada projeto, o professor faz a avaliação de acordo com critérios pré estabelecidos e reflete a respeito dos encaminhamentos a serem tomados com relação à aprendizagem de cada aluno Celta.

Ressaltadas as interaçôes, vale destacar as características da avaliaçáo formativa, apresentadas por Threlfall (2005, p.55, tradução nossa), com o intuito de aclarar as açôes envolvidas no processo. Ele esclarece que avaliar para aprender:

(1) Está incrustado no processo de ensino e aprendizagem no qual é parte essencial; (2) Compartilha metas de aprendizagem com os alunos; (3) Auxilia os alunos a saber e reconhecer os padröes a almejar; (4) Promove feedback que leva os alunos a identificar o que deveriam fazer da próxima vez para melhorar; (5) Leva o professor a ter consciência de que todo aluno pode progredir; (6) Envolve professor e aluno em revisão e reflexão do desempenho e progresso dos alunos; (7) Envolve os alunos no processo de autoavaliação.

A partir do detalhamento das açóes concernentes à avaliação para a aprendizagem, cabe comentar a respeito do papel e desdobramentos de cada uma delas. Tratando-se da primeira característica, importa destacar a indissolubilidade do elo entre o processo de ensino e aprendizagem e o processo de avaliação. Ambos necessitam andar juntos para garantir a formaçáo do aprendente, alicerçada no comprometimento com sua aprendizagem. $O$ aperfeiçoamento e a efetivação do ensino exigem que o professor faça a avaliação de suas próprias açóes, para, repensando-as, propiciar ambiente mais favorável para a edificaçáo de novas 
aprendizagens. O trabalho pedagógico em sala de aula, para alçar melhores resultados, para favorecer o alcance dos objetivos de ensino, precisa ampliar os espaços para a aplicação da avaliação contínua, tanto pelo professor como pelo próprio aluno e pelos colegas.

Refletindo a respeito das práticas do curso Celta, nota-se a presença do processo avaliativo em todas as atividades proporcionadas aos alunos. Todas as açóes desenvolvidas estão em constante avaliação, em razão da interaçáo desenvolvida pelos tutores. Nas práticas de ensino, por exemplo, o tutor possui uma ficha com os critérios a serem avaliados relativamente à aula ministrada pelo aluno Celta. Esta ficha não tem por intuito atribuir notas, mas oferecer subsídios ao tutor para detectar onde o aluno está e o que ele pode fazer para alcançar as metas/padróes. É por esta razão que, após as anotaçóes feitas a respeito dos pontos fortes e dos pontos fracos do desempenho do aluno na aula ministrada, o tutor anota o resumo, tanto do desempenho quanto dos pontos do plano de aula e, ao final, verifica se ele está de acordo com os padróes, abaixo ou acima deles. Os colegas também possuem critérios avaliativos para a observaçáo das práticas realizadas pelo aluno em sua aula. Estes são preparados e dispostos em uma ficha pelo tutor e, posteriormente, são entregues antes de a aula começar. Esta ficha configura-se um exercício para os alunos Celta, pois precisam utilizar dos conhecimentos apropriados para observar e apreciar o trabalho levado a termo por seus colegas.

Findada a aula, o tutor fornece ao aluno outra ficha - contendo critérios diferentes daqueles propostos para os alunos observadores - para que ele faça sua autoavaliação. As observaçóes da aula, registradas pelos três integrantes - tutor, colegas e aluno -, são retomadas, analisadas e discutidas no momento do feedback, quando as consideraçóes acerca do que foi observado sáo feitas e as decisóes a respeito do desempenho dos alunos avaliados são tomadas. Após o feedback, o aluno recebe as fichas de avaliaçáo para ler os comentários consignados.

A partir da reflexão da primeira característica, proposta por Threlfall (2005) para a avaliação formativa, cumpre avançar e comentar a respeito da segunda, a ser considerada como iniciadora e gerenciadora de todo o processo. O professor deve estabelecer metas a serem alcançadas pelos alunos. E, por isso, se há necessidade de tornar o aluno um dos responsáveis por sua aprendizagem, é indispensável compartilhá-las com ele, afinal não se chega a lugar algum sem saber para onde ir. E é por esta razáo que a terceira característica decorre da segunda. Os caminhos para a aprendizagem ficam muito mais fáceis e organizáveis quando se sabe o que se quer/precisa concretizar. Portanto, a elaboração de objetivos - que traduzam 
competências desejáveis - para com a formação é elemento essencial da avaliação formativa.

No Celta, antes das aulas iniciarem, o aluno recebe o programa do curso com todos os objetivos apresentados. Além disso, ao receber o seu caderno para a elaboraçáo do portfólio, ele tem a oportunidade de visualizar os objetivos a serem avaliados por ele e pelo tutor, no decorrer e no final do curso.

Os quatro projetos desenvolvidos também dispóem de objetivos a serem alcançados. Um fato interessante e rico na área de projetos é que, ao fazer os encaminhamentos necessários para a sua elaboração, os tutores explicitam, primeiramente, os objetivos a serem alcançados para, depois, apresentar os seus componentes. Eles enunciam objetivo por objetivo, tiram as dúvidas com relação a eles e, então, explicam os componentes que auxiliarão no alcance das metas/padróes estabelecidos.

Além dos objetivos do portfólio e dos projetos, vale ressaltar as metas elaboradas em decorrência do feedback de cada aula ministrada na prática de ensino. Ao analisá-las, durante todo o curso, observa-se que, ao final, cada aluno Celta conclui com metas/padróes a serem alcançados para a próxima prática. Por esta razáo, afirma-se a veracidade do compromisso do curso com a formaçáo de educadores construtores do conhecimento, porque atrelados a uma avaliação preocupada com a aprendizagem, com o avanço, com a superaçáo das dificuldades.

No que diz respeito à quarta característica da avaliação formativa, a promoçâo de feedback é elemento chave para impulsionar os próximos passos a serem dados pelos alunos. Compartilhando desta ideia, Black e Wiliam (1998, p. 6, traduçáo nossa) referem-se ao feedback como mantenedor de três componentes indispensáveis, a saber: "(1) reconhecimento da meta desejada; (2) evidência sobre a posição presente (desenvolvimento presente); (3) compreensão de uma maneira de unir ambos (componentes 1 e 2)".

Segundo os autores, estes três componentes necessitam ser reconhecidos pelo professor e pelos alunos antes de fazerem qualquer movimentaçáo no sentido de melhorar a aprendizagem. O professor resgata as metas estabelecidas para, com base nas evidências coletadas nos procedimentos avaliativos, apresentar ao aluno a sua posiçáo em relação ao processo de aprendizagem e concretização das metas. Vale ressaltar que o aluno e seus colegas podem, da mesma forma, chegar aos resultados de sua aprendizagem por meio da autoavaliaçáo. A partir de entâo, o professor remete ao terceiro componente do feedback, ou seja, traça atividades com o propósito de levar o aluno à superaçáo das dificuldades.

Nas práticas de ensino proporcionadas pelo curso Celta, o feedback configura-se momento essencial para o fechamento da aula. A partir da coleta de informaçôes, 
feita tanto pelo professor quanto pelo aluno e seus colegas, encontram-se as evidências para a discussão dos pontos fortes e fracos do desempenho do aprendente. Nesse momento, todos fazem o resgate de suas anotaçóes para propor discussóes, reflexóes e sugestóes de aprimoramento. O professor retoma, também, as metas traçadas na prática anterior a seu estágio de superaçâo. Se ainda pendentes, abre-se ao grupo a oportunidade de discutir novos caminhos.

Observa-se no feedback das atividades, durante o curso Celta, um momento rico de compartilhamento de ideias e de aprendizagem. E este é o princípio para tornar o aluno responsável por sua formação. Para Nicol e Macfarlane-Dick (2006), é muito difícil imaginar o desenvolvimento da avaliaçáo formativa se ela estiver inteiramente nas mãos do professor. Como progredir sem fazer parte do processo de avaliação do próprio desenvolvimento? Como evoluir sem se sentir parte do processo de aprendizagem? Para o autor, a promoçáo de feedback é primordial, porém se efetuada da maneira correta. Ele precisa ser baseado em discussóes acerca do apresentado, e não somente em "[...] transmitir mensagens aos alunos sobre o que está certo e o que está errado no seu trabalho, seus pontos fortes e fracos" (Nicol; Macfarlane-Dick, 2006, p. 200, tradução nossa).

É importante destacar que, durante o feedback, os alunos precisam realizar o exercício de comparação da sua posição em relação ao conhecimento atingido no momento e o padrão a ser alcançado, pois necessitam que esta brecha seja fechada (Nicol; Macfarlane-Dick, 2006). E é por esta razão que se torna indispensável ao aluno possuir habilidades avaliativas, como o professor, para poder avaliar o seu próprio desempenho (Sadler, 1989). Para Fernandes (2009, p. 55), “[...] os professores devem partilhar o poder de avaliar os alunos e devem utilizar uma variedade de estratégias, técnicas e instrumentos de avaliaçáo". Assim, avaliar não pode ser uma via de máo única e, portanto, adstrita ao professor. $\mathrm{O}$ aluno deve participar, avaliando os pares e a si mesmo, comprometendo-se com a superaçáo das próprias dificuldades, empreendendo esforços para aprender o que ainda náo sabe. Por sua vez, o professor precisa recompor o ensino, diversificando as formas de concretizálo; afinal, se o aluno não aprendeu o conteúdo quando foi abordado em um dado formato, é recomendável alterar esse formato - diversificando estratégias, propondo outras técnicas - no intuito de ampliar as condiçóes para a aprendizagem.

No curso Celta, uma das maneiras de envolver o aluno é pela promoção de atividades que exercitem nele a habilidade avaliativa. Estas ocorrem durante as sessóes de input. Em determinado momento do curso, eles sáo divididos em dois grandes grupos para procederem à avaliação do curso. Para tanto, cada grupo recebe uma folha com alguns tópicos a serem analisados, e um secretário é eleito para a ano- 
tação das ideias propostas pelos pares. Os alunos discutem cada tópico e refletem acerca dos pontos positivos e negativos de cada um. É um exercício bastante complexo, pois, muitas vezes, a ideia posta náo encontra unanimidade, mas necessita alcançar - pelo menos - a concordância de todos os integrantes, exigindo maior clareza e aprofundamento nos argumentos. As anotaçóes a respeito dos tópicos discutidos sáo encaminhadas para o coordenador do curso, pretendendo oferecer-lhe subsídios para possíveis alteraçóes nos encaminhamentos didáticos.

A fim de tornar possível a composiçáo de tais atividades, o professor deve reconhecer que todo aluno é capaz de gerir os próprios esforços no intuito de progredir. Um dos pontos nodais da avaliação formativa é a corresponsabilização do educando na gestão de seus percursos de aprendizagem, não somente por ser capaz de reconhecer - sozinho ou com a ajuda de outrem - as próprias dificuldades, mas, principalmente, por poder empreender esforços no sentido de superaçáo e desenvolvimento. O que faz lembrar Saviani (2001), quando ressalta que o homem, como ser aprendente, é capaz de estabelecer relaçóes e realizar superaçôes, mas, para isso, precisa reconhecer suas potencialidades. $\mathrm{Na}$ escola, este reconhecimento se dá por meio da ação orientada para a promoção da aprendizagem e do desenvolvimento, fundamentando-se em uma perspectiva formativa de avaliação.

O papel do professor não pode ser minimizado, apesar da relevância conferida à responsabilidade do educando. O professor é elemento muito importante - mas náo central - no processo avaliativo, pois será ele o organizador das açóes em sala de aula para promover a aquisição, a ampliaçáo e a recuperação de saberes. Importa destacar que, mesmo com a relevância da tomada de decisóes pelos colegas e pelos próprios alunos ao realizarem a autoavaliação, é o professor o norteador dessas açōes. Assim, seu papel é essencialmente o de orientador, o de gestor do processo educativo.

Ao analisar a postura dos tutores no curso Celta, notam-se características do educador compromissado em promover práticas formativas com os alunos. Ao realizar as sessóes de input, primeiramente, os tutores investigam o que os alunos já sabem, valendo-se de diferentes atividades. A utilização do conhecimento prévio caracteriza-se importante ferramenta para "[...] ajustar sistematicamente o ensino de acordo com as (suas) necessidades" (Fernandes, 2009, p. 59). Assim, as exposiçóes de conteúdo e atividades individuais ou grupais proporcionadas são, sempre, efetivadas de maneira a assegurar argumentaçóes e discussóes com/entre os alunos, para que busquem e alcancem o conhecimento.

Um fato interessante é a maneira de consecução dessas atividades. As mesmas sáo realizadas de acordo com o propósito de formação de professores da língua 
inglesa no Celta. Ou seja, a base para todos os trabalhos está nos objetivos a serem atingidos, constituindo os tutores um exemplo para os alunos quanto à postura, às atitudes, às formas de lidar com as questóes e os problemas táo presentes no cotidiano da sala de aula. Talvez por isso, ao final de cada atividade, o feedback esteja presente, como um compromisso para delimitar a distância entre o realizado e o desejado e, da mesma forma, como uma possibilidade para tracejar a aproximaçáo desses dois pontos: o real e o possível.

O professor deve envolver os alunos no processo e levá-los a refletir a respeito do seu desempenho. Esta é a sexta característica da avaliaçáo formativa, delineada por Threlfall (2005). Porém, as decisões tomadas, tanto pelo professor quanto pelos alunos, devem ser prudentes. Álvarez Méndez (2002, p.79) alerta:

Qualquer decisão adotada deve estar bem-fundamentada e bem-argumentada, sendo a prudência uma característica crucial que impóe agir razoavelmente a favor do sujeito que aprende e levando-se em conta as consequências que qualquer decisão pode acarretar para ele.

Há necessidade, portanto, de refletir a respeito dos resultados, evidenciados pelas informaçôes coletadas na observação ou em outras práticas avaliativas, por ambas as partes do processo de ensino e aprendizagem: professor e aluno. Desse modo, um e outro terão fundamentaçáo para as decisóes pensadas e efetivadas com relação à aprendizagem. Estas estarão sempre embasadas nas metas a serem alcançadas.

O Celta, em sua consecuçáo, revela grande preocupação e cuidado com a promoção de reflexóes acerca dos resultados e prudência na tomada de decisóes, trabalhando com a elaboraçáo de um portfólio juntamente com os alunos. Mas, por que o portfólio? Hernández (1998), ao tecer consideraçóes relativamente a este instrumento avaliativo, destaca a visualizaçáo das evidências da aprendizagem do aluno e das estratégias utilizadas por ele para a sua concretização. Por esta razáo, o portfólio torna-se efetivo para pensar e tomar decisóes, pois agrega produçóes de alunos e professores, explicitando dificuldades e progressos (Vilas Boas, 1998).

A elaboraçáo do portfólio no curso possibilita a avaliação dos objetivos pelo aluno e pelo tutor, tanto no decorrer quanto no final do curso. Todavia, olhar as tarefas compiladas e os registros de observaçáo acumulados não se configura um ponto final, mas uma breve parada para compreender o que foi e delimitar o que virá. A reflexão e a superação são balizas reveladoras do compromisso formativo.

A sétima e última característica enunciada por Threlfall (2005), para caracterização da avaliação formativa, concerne ao envolvimento dos alunos na autoavaliação. 
Segundo o autor, os alunos devem estar aptos a selecionar estratégias e movimentos apropriados para trazer seu próprio desempenho para mais perto das metas a serem alcançadas. E, para a concretizaçáo de tal ação, a autoavaliação é ferramenta essencial. Black e Wiliam (1998, p.6, tradução nossa), ao dialogarem a respeito desse instrumento, ainda acrescentam: "[...] se a avaliação formativa é para ser produtiva, os alunos devem ser envolvidos a fazer a autoavaliação para que possam entender o principal propósito de sua aprendizagem e entáo compreender o que eles precisam fazer para alcançá-la".

É por intermédio da autoavaliação que os alunos Celta tornam-se capazes de identificar o porquê de suas açôes e pensar estratégias para concretizar superaçóes. A ficha que recebem, após cada prática de ensino, é composta de perguntas para instigar o seu raciocínio com relaçáo ao desempenho evidenciado durante a aula ministrada: (a) Com quais açóes está satisfeito?; (b) Com quais açóes não está contente?; (c) Quais eram os objetivos de sua aula para com os alunos?; (d) Na sua opinião, os objetivos foram alcançados?; (e) $\mathrm{O}$ que você aprendeu com esta aula? e (f) Alguma pergunta para fazer ao tutor? (Oxford House College, 2010, tradução nossa). A contribuição das respostas conferidas a estas perguntas durante o feedback se faz necessária, primeiramente para "obrigar" o aluno a olhar suas realizaçóes, aquilatando o que fez, como e com quais resultados e, também, para que, compreendendo e apreciando o alcançado, seja capaz de estabelecer novas metas e empreender estratégias para atingi-las.

Outra prática desenvolvida no curso, em relação à autoavaliaçáo, é o quarto projeto realizado. Intitulado "Liçóes da sala de aula" (University of Cambridge, 2010 , p. 23), o projeto integra as aprendizagens adquiridas pelo aluno durante o curso, os seus pontos fortes e os seus pontos fracos. Como este é o último projeto a ser entregue pouco antes do término do curso, os pontos destacados pelo aluno com relação ao seu desempenho seráo aqueles superados ou que ainda necessitam de aperfeiçoamento. Portanto, após o seu detalhamento, o aluno propóe formas de trabalho para sobrepujar pontos fracos, por meio de pesquisas e auxílio dos tutores. Por fim, o aluno tece consideraçóes acerca da continuação de seus estudos como educador após o término do curso. Para isso, é preciso que pesquise outras maneiras de continuar estudando.

Os objetivos para com este último projeto, juntamente com a sua realização, remetem a uma das atividades inerentes ao processo de avaliação formativa, destacada por Scallon (2000): a utilização de uma tarefa complexa. Este termo é composto de significativas consideraçôes acerca do compromisso com a aprendizagem. Ao efeti- 
var uma tarefa complexa, o professor intenta fazer com que o aluno utilize todos os conhecimentos e habilidades apropriados até o momento para resoluçáo de um problema ou para a realizaçáo de uma tarefa, procurando efetuar relaçóes, discussóes e reflexóes.

Para Scallon (2000, p. 162), a tarefa corresponde a uma aproximação do objetivo final para com a aprendizagem e "[...] deve corresponder ao nível de competência e às características dos alunos em geral". Para tanto, o autor ainda acrescenta:

A pertinência do projeto deve ser explicada para suscitar a motivação dos alunos; as dificuldades a serem superadas devem ser percebidas de maneira tal que os alunos experimentem uma sensação de "controle" da tarefa; aqui diversas regulagens são possíveis e até podem ser antecipadas durante o planejamento.

O percurso da tarefa deve suscitar as capacidades dos alunos, bem como a leitura para alcançar os resultados. Ela deve ser "objeto de regulação" (Scallon, 2000) para promover desenvolvimento, aperfeiçoamento e superaçóes pelos alunos. Por essa razão, o último projeto desenvolvido no Celta configura-se uma tarefa complexa, pois exige análise e reflexão a respeito dos conteúdos e atividades trabalhados no curso, em congruência com o próprio processo de aprendizagem do aluno. Este precisa estabelecer relaçóes entre: (a) os conhecimentos construídos desde o início do curso, (b) seu desenvolvimento enquanto profissional, e (c) o referencial teórico pesquisado para as proposiçóes do projeto.

A proposta provoca inquietaçóes e suscita uma posição do aluno em relação ao seu desenvolvimento e às suas açóes futuras como professor de língua inglesa. Faz com que olhe para suas próprias capacidades, para seu próprio processo de aprendizagem. Orienta caminhos, produz reflexáo e novos conhecimentos, problematiza, promovendo açóes próprias de uma tarefa complexa, voltada para fins formativos.

Apresentado o conceito da avaliação formativa, particularizadas as suas características, cumpre abordar, também, a questão relativa à importância e às possibilidades inerentes aos procedimentos de coleta de informaçóes para proceder à avaliação. De acordo com Álvarez Méndez (2002, p. 78), com base na elaboração das metas a serem alcançadas, é preciso estabelecer as formas de coleta das informaçóes, pois, para o autor:

Importa que a informaçáo obtida da avaliaçáo seja o ponto de referência para a ação didática, fornecendo informaçáo valiosa sobre os progressos reais de quem está aprendendo, em que sentido e direção o faz, as dificuldades que encontra e o modo de superá-las e com que profundidade e consistência, através de perguntas que obriguem à argumentação. 
A proposição do autor remete a algumas consideraçōes relevantes a respeito da dinâmica da avaliação formativa. A primeira configura-se no detalhamento que o autor faz da interaçáo proposta por Black e Wiliam (2009) em sala de aula (iniciação - resposta - avaliação). Em suma, a interpretação da dinâmica nas bases de Álvarez Méndez (2002) seria: coleta de informaçōes - avaliaçáo - tomada de decisão (ou input, output e feedback).

A segunda consideração refere-se à importância da escolha dos instrumentos de avaliação para a obtençáo das informaçōes, a fim de refletir e concretizar a açáo didática. Silva (2004, p. 66), ao dissertar a respeito da utilizaçâo de instrumentos avaliativos, salienta a importância de não se ter somente uma forma de avaliar os saberes do aluno, mas sim várias, "[...] pois quanto maior for o seu número, mais tipos de informações poderão ser coletadas, possibilitando uma melhor compreensão e intervençáo sobre o objeto avaliativo". O uso de diversos instrumentos avaliativos para a coleta de informaçóes é função estratégica (Silva; Hoffman; Esteban, 2003) para constatar a efetividade do ensino, a validade da aprendizagem e o rumo traçado pelos caminhos tomados.

Ao tratar de instrumentos avaliativos, Richards (1999) faz cinco grandes observaçóes a serem refletidas anteriormente à atividade de coleta de informaçóes e à avaliação. A primeira é: por que avaliar? Responder a tal indagaçáo demanda ter clareza quanto aos propósitos da apresentaçáo dos temas em decorrência mesmo de suas possibilidades de utilização. A segunda é: o que avaliar? Afinal, não se pode avaliar qualquer coisa, mas apenas os conteúdos - conceituais, procedimentais e atitudinais - ensinados em função dos objetivos traçados como fundamentais. Portanto, torna-se imprescindivel identificar os tipos de informaçáo que seriam úteis para tais propósitos. A terceira: como avaliar? Decidir como avaliar para melhor coletar os dados. Entáo, após as perguntas, selecionar instrumentos adequados para cada situação (quarta observaçáo) e, depois, preparar o feedback (quinta observação). Assim, o professor poderá checar progressos, identificar dificuldades e, então, planejar intervençóes apropriadas.

Os instrumentos avaliativos utilizados no curso Celta são:

1. Observação: este instrumento é utilizado em diferentes momentos do curso com o intuito de coletar informaçóes sobre comportamento, atitudes ou habilidades a serem examinadas sobre circunstâncias específicas (Richards, 1999). Esta foi utilizada nas práticas de ensino pelos tutores, alunos e colegas de sala mediante fichas. É relevante destacar a importância destas para a realizaçáo da observação, pois: 
[...] se a observaçáo é para ser efetiva no processo de aprendizagem, ela precisa ser objetiva. Para ser objetiva, ela requer estrutura. É preciso ter um plano, um objetivo e um guia para ser seguido. É preciso estar consciente do que exatamente você está procurando. (Reed; Bergermann, 2005, p. 19, traduçáo nossa)

Além das práticas de ensino, a observação também é utilizada nas sessóes de input pelos tutores e nas visitas dos alunos Celta às classes ministradas por professores experientes. Para tanto, os alunos recebem fichas com os critérios a serem observados. Os instrumentos de observação utilizados em ambas as atividades descritas pautam-se por registros de informaçóes e checklists.

2. Projetos: trabalhos escritos que sáo, na verdade, outra forma de fazer a avaliação para a aprendizagem do aluno. Este instrumento fomenta pesquisas e reflexóes acerca da área de ensino da língua inglesa, auxiliando os tutores a detectarem pontos positivos e pontos a superar com relação ao desempenho do aluno Celta.

3. Autoavaliação: instrumento promotor de reflexáo e que, em certa medida, procura assegurar a corresponsabilização e autogestáo do aluno na conduçáo do seu processo de aprendizagem.

4. Avaliação dos colegas de sala: outra possibilidade de promoção de reflexão e aprendizagem, pois, ao contemplar e analisar as realizaçóes dos pares na consecução de experiências de ensino, cada um pode apropriar-se de práticas e alternativas de ação docente.

5. Portfólio: pasta de documentos que pretende oferecer um olhar longitudinal sobre as realizaçóes do aluno. Contemplar seus registros favorece ao aluno e ao professor melhor desvendarem as aprendizagens alcançadas e aquelas a serem atingidas.

A aplicação de instrumentos avaliativos formais e não formais (UR, 1996) se faz necessária para que, assim, os alunos apresentem resultados fidedignos. A avaliaçáo contínua deve ser feita de forma construtiva, visando ao desenvolvimento - não à reprovaçōes - e deve permitir aos alunos demonstrarem seus saberes. Portanto, o professor precisa estar consciente de que, quando avalia o aluno, precisa ter, antes de tudo, um critério a seguir, um planejamento do que será avaliado, antes de fazêlo. Porém, os critérios utilizados para a realização de uma avaliação considerada formativa não devem ser orientados por notas. Se realizado desta forma, o professor 
estaria colaborando para a classificaçáo de seus alunos, e náo para o alcance das metas estabelecidas.

William e Thompson (2007 apud Black; Wiliam, 2009, p. 8) apresentam um resumo (Figura 1) dos conceitos relacionados à avaliaçáo formativa, juntamente com o aclaramento do papel desempenhado por professor, aluno e colegas de classe no decurso desse processo:

Figura 1 - Resumo dos conceitos de avaliação formativa

\begin{tabular}{|l|l|l|l|}
\cline { 2 - 5 } \multicolumn{1}{c|}{} & \multicolumn{1}{|c|}{$\begin{array}{c}\text { Para onde o aluno } \\
\text { está indo }\end{array}$} & $\begin{array}{l}\text { Onde o aluno está } \\
\text { neste momento }\end{array}$ & $\begin{array}{c}\text { Como chegar lá } \\
\text { (meta/padräo) }\end{array}$ \\
\hline Professor & $\begin{array}{l}\text { Esclarecer intenções } \\
\text { de aprendizagem e } \\
\text { critérios para o } \\
\text { sucesso. }\end{array}$ & $\begin{array}{l}\text { Engendrar discussões } \\
\text { efetivas em sala de } \\
\text { aula e outras } \\
\text { atividades que } \\
\text { forneçam evidências } \\
\text { da aprendizagem do } \\
\text { aluno. }\end{array}$ & $\begin{array}{l}\text { Promover feedback } \\
\text { que mova os alunos } \\
\text { à frente no processo. }\end{array}$ \\
\hline Colega de classe & $\begin{array}{l}\text { Compreender e } \\
\text { compartilhar as } \\
\text { intenções de } \\
\text { aprendizagem e os } \\
\text { critérios para o } \\
\text { sucesso. }\end{array}$ & $\begin{array}{l}\text { Ser recurso } \\
\text { instrucional para o } \\
\text { outro. }\end{array}$ & $\begin{array}{l}\text { Ser recurso } \\
\text { instrucional para o } \\
\text { outro. }\end{array}$ \\
\hline Aluno & $\begin{array}{l}\text { Compreender as } \\
\text { intenções de } \\
\text { aprendizagem e os } \\
\text { critérios para o } \\
\text { sucesso. }\end{array}$ & $\begin{array}{l}\text { Detentor da própria } \\
\text { aprendizagem. }\end{array}$ & $\begin{array}{l}\text { Detentor da própria } \\
\text { aprendizagem. }\end{array}$ \\
\hline
\end{tabular}

Fonte: William; Thompson, 2007 apud Black; Wiliam, 2009, p. 8, tradução nossa.

Ao analisar a apresentaçáo dos conceitos de avaliação formativa, nota-se um movimento inacabado entre as funçóes do professor, do colega de classe e do aluno. Entendendo inacabado no sentido de possibilidade de aperfeiçoamento e superação, na perspectiva de que para o alcance dos novos objetivos traçados, aqueles já abordados são retomados sob novo ponto de vista - em situaçóes diversas, com técnicas variadas. $\mathrm{O}$ desenvolvimento destes movimentos dependerá das discussóes e reflexóes feitas pelos envolvidos no processo.

O quadro síntese elaborado por William e Thompson (2007, apud Black; Wiliam, 2009) elucida o papel daqueles designados como agentes da aprendizagem. São agentes por trabalharem pela aprendizagem por meio do agir constante, conscientes do ponto de chegada pretendido. Porém, a efetivação deste trabalho 
depende do orientador e mediador de todo o processo: o professor. O complexo conjunto de açôes que envolvem a avaliação para a aprendizagem só será possível se pensado e planejado pelo educador.

Os resultados finais para os alunos Celta são alcançados mediante um grande conjunto de práticas formativas. Ao final do curso, cada aluno recebe o seu parecer com todos os objetivos propostos e a posiçâo final em relação a cada um. Esta avaliaçáo é composta por: (a) AS+: acima do padráo +; (b) AS: acima do padráo; (c) S: padrão; (d) S-: padráo -; e (e) NS: abaixo do padrão. Há também um parecer emitido pelo tutor, com consideraçóes a respeito do desempenho do aluno durante o curso.

Nota-se, com a apresentação deste parecer, a preocupação e o esforço em garantir que o aluno Celta aprenda. Não lhe sáo informadas notas ou estrelinhas de trabalhos e testes que, somadas umas às outras, resultam na condiçáo de aprovado/reprovado, dependendo de sua média. E esta náo considera as aprendizagens edificadas, as competências formadas, mas apenas se as notas estabelecidas como mínimas foram atingidas ou não. $\mathrm{O}$ parecer Celta náo consiste na média aritmética ou ponderada de aprendizagens e realizaçóes, mas em avaliar a aproximaçáo do educando na consecução dos objetivos considerados essenciais.

Mesmo tendo um caráter de terminalidade, conferindo aprovação ou reprovação, o parecer supera a perspectiva classificatória e assume a perspectiva formativa, quando favorece a reflexáo e superação. Neles constam os objetivos considerados essenciais para constituição da competência para o ensino de língua inglesa. Aqueles que foram parcialmente atingidos são indicados, permitindo ao aluno empreender esforços para alcançá-los.

Todavia, cumpre lembrar que o processo constante e evolutivo das tarefas avaliativas propicia um ambiente favorável à recomposiçáo do ensino, bem como à reflexão acerca do como está se efetivando a aprendizagem - tanto pelo professor quanto pelos alunos - para se assegurar o alcance do produto, ou o resultado desejado. Reconhecendo que náo basta investir no processo sem ter por meta um ponto de chegada. Este precisa ser trazido à luz.

A tarefa complexa é uma alternativa pertinente à elucidaçáo do aprendido. A análise dos projetos elaborados pelos alunos Celta, sem desconsiderar quanto, como e em que evoluíram no decorrer do curso - aspectos evidenciados no portfólio, nos registros de observação, nos instrumentos de autoavaliação, dentre outros, oferecem relativa clareza acerca do alcance ou não dos objetivos traçados.

A atribuiçáo de letras para os aprovados, talvez seja a única crítica negativa a ser feita a respeito do Celta. Por mais que os pareceres tenham natureza formativa, 
uma vez que indiquem os objetivos não alcançados ou parcialmente atingidos, bem como contenham comentários e sugestóes do tutor, mesmo que não expressem médias - táo ao gosto da classificação - concentrando-se na descriçáo do alcançado, eles ainda rotulam, quando subdividem aqueles que atingiram os objetivos como: aluno $\mathrm{A}$, aluno $\mathrm{B}$ ou aluno $\mathrm{C}$.

Qual a finalidade de estabelecer esta hierarquia? Por que $\mathrm{A}$ é mais que $\mathrm{B}$ ou $\mathrm{C}$ ? Por que $C$ é menos que $A$ ou $B$ ? Este seria um ponto necessário de mudança para a completude da avaliaçáo formativa no curso. Silva (2004, p. 75) aponta para a utilização de letras como "[...] mecanismo de classificação de alunos", e ainda acrescenta que isto "[...] tem colaborado para a institucionalização de práticas de discriminaçáo e de exclusão dos aprendentes".

O parecer concedido aos alunos Celta traz a conclusão a respeito de cada objetivo proposto e as consideraçóes do tutor. Por esta razáo, a utilização das condiçóes apto e não apto seria suficiente para informar as capacidades desenvolvidas pelo aluno ou aquelas que ainda necessitam de aprimoramento. Além do mais, a realização da tarefa complexa (Scallon, 2000), efetuada no último projeto pelos alunos, proporciona reflexóes acerca de propostas e sugestóes de ações, por eles próprios, para os pontos a superar. Nesse sentido, a prescrição das letras no que concerne à aprovação dos alunos se faz desnecessária.

Contudo, as consideraçôes feitas a respeito do curso, em congruência com o referencial teórico, mostram que, ao proporcionar as atividades formativas descritas, o Celta quer formar educadores responsáveis pela aprendizagem e conscientes dos benefícios da realizaçáo de práticas avaliativas formativas. Todo este complexo se faz exemplo para os alunos, futuros professores, na esperança de usufruírem do conhecimento adquirido em sua prática.

\section{ALINHAVANDO APRENDIZAGENS... TECENDO CONSIDERAÇÕES...}

$O$ estudo realizado possibilitou retomar um caminho empreendido em um país estrangeiro e trazê-lo para o aqui. É bom olhar o passado e com ele aprender. É relevante recuperar uma vivência, desvelando-a e analisando-a tendo por baliza o referencial teórico. É importante reaprender o aprendido, sob uma nova ótica em um outro momento. E foram inúmeras as aprendizagens edificadas.

- “[...] teoria e prática constituem um todo único, produzido na dinâmica da evoluçáo humana em um contexto e em um tempo" (Souza, 2000, p.30). Não há prática comprometida com o processo de humanização sem a teoria fornecedora de subsídios propensos à açáo, análise e refle- 
xão, assim como não há teoria desvencilhada de toda e qualquer prática comprometida.

- A realidade do que se pesquisa precisa ser vivida. Analisá-la e refletir em relaçáo a ela, em sua completude e profundidade, só é possível quando nela o pesquisador imerge.

- Planejamento é o solo fértil para o nascer de bons frutos. Tratar da realidade com comprometimento exige açóes pensadas e organizadas em um todo produtivo. Conhecer a realidade, elaborar, executar e aperfeiçoar planos denotam agir responsável.

- Mais do que dar bons frutos, planejar envolve atribuir-lhes significado. Um planejamento relevante é aquele empenhado em promover análises, reflexóes, aprendizagem. Aquele que propicia objetivos desejáveis, valorizando e atribuindo sentido às açóes.

- Não é possível elaborar um plano sem ter clareza em relação aos objetivos a serem alcançados. Para a efetividade de uma avaliaçáo formativa, esta etapa é indispensável para o encaminhamento de todas as outras.

- O alcance dos objetivos permite conhecer o aluno. Em um contexto formativo, as atividades fornecem subsídios ao professor para saber qual será o próximo passo em relaçáo à aprendizagem de cada um.

- Dar significado à aprendizagem é promover a participação dos envolvidos no processo. Só nos tornamos parte de algo quando participamos ativamente.

- Saber onde se está, onde se quer chegar e qual caminho tomar a favor da aprendizagem é compromisso da parceria professor-aluno a traduzir-se na expressão feedback construtivo.

- Os cursos de formaçáo de professores ainda fazem pouco. É preciso olhar para esta realidade e nela desenvolver açóes formativas.

Mudanças requerem construçóes e reconstruçóes, almejando processos consistentes - náo ralos ou destituídos de sentido - e resultados melhores. Por isso, mais que constatar é preciso propor, razão pela qual algumas sugestóes propostas visam a abrir caminhos de possibilidades para aqueles que pretendam empreender uma prática avaliativa mais comprometida com a aprendizagem e o desenvolvimento do educando. Sáo elas:

a) apresentar os objetivos a serem alcançados. Embora estejam explicitados no programa da disciplina, é papel do professor expô-los aos alunos e, talvez, 
destrinchá-los, a fim de torná-los plausíveis de interpretação e de obter processos e resultados mais concretos;

b) estabelecer critérios de avaliaçáo a cada atividade realizada para promover visualização das reais habilidades e/ou conhecimentos exigidos;

c) diversificar os instrumentos avaliativos. Utilizar-se de diferentes instrumentos para avaliar a aprendizagem é colaborar para uma formaçáo real, favorável ao desenvolvimento e aperfeiçoamento dos aprendentes;

d) utilizar a autoavaliação sem se ater à autoanotaçáo;

e) utilizar a avaliação pelos pares, principalmente após apresentações de trabalhos ou términos de atividades escritas;

f) promover feedback coletivo e/ou individual, após as atividades, apresentando pontos fortes e dificuldades reais;

g) utilizar os resultados da aprendizagem dos alunos para replanejamento das atividades posteriores;

h) elaborar e realizar tarefa complexa como meio de promover oportunidade para a organização, análise e reflexâo dos conteúdos trabalhados, evitando os pequenos trabalhos ou os testes com recortes de conteúdos. O professor precisa despreocupar-se com as médias para concentrar-se na valorização de uma avaliação final;

i) emitir pareceres a respeito da aprendizagem dos alunos, em conformidade com os objetivos traçados para a disciplina ou para determinado período dela.

As sugestôes podem levar os atuais e futuros educadores a construírem caminhos necessários a serem tomados para favorecer $o$ alcance da aprendizagem, valendo-se de uma avaliaçáo formativa. Faz-se importante ressaltar que as sugestóes elaboradas aplicam-se para a utilização de práticas formativas no ensino de língua inglesa, enfatizando a importância de sua concretizaçâo para um processo de ensino e aprendizagem efetivo.

Mergulhar em profundas aprendizagens é entranhar-se em novas descobertas, é penetrar em conflitos, cravar consideraçōes. A pesquisa permitiu desvelar a avaliação formativa como uma possibilidade concreta na sala de aula e necessária na formação de futuros educadores. Acima de tudo, por meio de todo um conjugado de açóes em relação a este tema, descortinou-se a necessidade da aplicação de atividades formativas no ensino em geral, principalmente na formaçáo de educadores. A avaliação formativa é elemento real e concretizável em sala de aula e depende de atitudes conscientes e comprometidas do educador, este que precisa se tornar pesquisador da própria açăo para desenvolver e aperfeiçoar capacidades e resultados. 


\section{REFERÊNCIAS BIBLIOGRÁFICAS}

ÁlVAREZ MÉNDEZ, J. M. Avaliar para conhecer, examinar para excluir. Tradução Magda Schwartzhaupt Chaves. Porto Alegre: Artmed, 2002.

BLACK, P.; WILIAM, D. Inside the black box: raising standards through classroom assessment. Phi Delta Kappan, v. 80, n. 2, Oct. 1998. Disponivel em: <www.pdkintl.org/kappan/kbla9810.htm>. Acesso em: 22 fev. 2010.

Developing the theory of formative assessment. Educational assessment, evaluation and accountability, Dordrecht, v. 21, n. 1, p. 5-31, Feb. 2009.

BLOOM, B. S.; HASTINGS, T.; MADAUS, G. Manual de avaliação formativa e somativa do aprendizado escolar. São Paulo: Pioneira, 1983.

DENZIN, N. K.; LINCOLN, Y. O Planejamento da pesquisa qualitativa: teorias e abordagens. São Paulo: Artmed, 2006.

FERNANDES, D. Avaliar para aprender: fundamentos, práticas e políticas. São Paulo: Unesp, 2009.

HARRIS, M.; McCANN, P. Assessment. Oxford: Heinemann, 1994.

HERNÁNDEZ, F. Transgressão e mudança na educação: os projetos de trabalho. Porto Alegre: Artmed, 1998.

MOREIRA, D. A. O Método fenomenológico na pesquisa. São Paulo: Pioneira Thomson, 2002.

NICOL, D. J.; MACFARLANE-DICK, D. Formative assessment and self-regulated learning: a model and seven principles of good feedback practice. Studies in higher education, Oxford, $v$. 31, n. 2, p. 199-218, Apr. 2006.

OXFORD HOUSE COLLEGE. London, 2010. Documentos e trabalhos apresentados.

PERRENOUD, P. Avaliação: da excelência à regulação das aprendizagens entre duas lógicas. Porto Alegre: Artmed, 1999.
REED, A. J. S.; BERGERMANN, V. E. A Guide to observation, participation, and reflection in the classroom. New York: McGraw Hill, 2005.

RICHARDS, J. C. Classroom-based evaluation in second language education. Cambridge: CUP, 1999, p. 76-97.

SADLER, D. R. Formative assessment and the design of instructional systems. Instructional Science, n. 18, p. 119-144, 1989.

SAVIANI, D. Escola e democracia. 34 ed. Campinas: Autores Associados, 2001.

SCALLON, G. Avaliação formativa e psicologia cognitiva: correntes e tendências. In: GRÉGOIRE, J. (Org.). Avaliando as aprendizagens. Porto Alegre: Artmed, 2000, p. 155-168.

SILVA, J. F.; HOFFMAN, J.; ESTEBAN, M. T. (Org.). Práticas avaliativas e aprendizagens significativas em diferentes áreas do currículo. Porto Alegre: Mediação, 2003.

SILVA, J. F. da. Avaliação na perspectiva formativa-reguladora. Pressupostos teóricos e práticos. Porto Alegre: Mediação, 2004.

SOUZA, N. A. de. Sol e sombra: a relação teoriaprática na formação do professor. Contexto Educação, ljuí, n. 58, p. 25-41, abr./jun. 2000.

THRELFALL, J. The Formative use of assessment information in planning - the notion of contingent planning. British Journal of Educational Studies, York, v. 53, n. 1, p. 54-65, Mar. 2005.

UNIVERSITY OF CAMBRIDGE. CELTA syllabus. 2010. Disponivel em: <http://www. cambridgeesol.org/exams/teaching-awards/ celta.html >. Acesso em: 14 maio 2010.

UR, P. A Course in language teaching - practice and theory. Cambridge: CUP, 1996, p.33-44.

VILAS BOAS, B. M. F. O Projeto políticopedagógico e a avaliação. In: VEIGA, I. P. A.; RESENDE, L. (Orgs.). Escola: espaço do projeto político-pedagógico. Campinas: Papirus, 1998. 